\title{
Perceptual implicit memory requires attentional encoding
}

\author{
BRIAN T. CRABB and VERONICA J. DARK \\ Iowa State University, Ames, Iowa
}

\begin{abstract}
Perceptual implicit memory for previously attended and unattended words was measured either in a word-stem completion task or in a perceptual fluency (perceptual identification) task. Subjects ( $N=$ 144) first engaged in a focused attention task in which they were to identify one of two words presented for 100,200 , or $300 \mathrm{msec}$. Words were classified as attended if they were reported during the focused attention task and unattended if they were not. Results for both implicit memory tests indicated reliable perceptual implicit memory for attended words but not for unattended words, regardless of focused attention exposure duration. The results indicate that perceptual implicit memory tasks reflect attentional encoding processes; that is, words must undergo attentional encoding if they are to affect performance on a later perceptual implicit memory test.
\end{abstract}

Implicit memory is the phenomenon in which previously encoded information affects performance on some task without the individual's consciously recollecting the information. This nonconscious, automatic retrieval contrasts with the conscious, effortful retrieval that occurs during an explicit memory test such as recognition or recall. A number of different implicit memory tests have been identified, and they have been classified into two broad categories: conceptual and perceptual. Category exemplar production, general knowledge tests, and spelling tasks are considered to be conceptual implicit memory tests; perceptual fluency (also termed perceptual identification), word-stem completion, and word-fragment completion are considered to be perceptual implicit memory tests (e.g., Roediger, 1990; Roediger, Weldon, \& Challis, 1989). Conceptual implicit memory tests often are affected by encoding variables that affect explicit memory tests, whereas perceptual implicit memory tests are not affected by these variables.

Attentional processing at encoding is assumed to be necessary to produce explicit memory for the encoded information (see, e.g., Fisk \& Schneider, 1984; Rock \& Gutman, 1981; Shiffrin \& Schneider, 1977). The necessity of attentional processing at encoding also has been demonstrated for conceptual implicit memory tests (e.g., Mulligan, 1998; Mulligan \& Hartman, 1996). It has been

\footnotetext{
The 100-msec conditions of this study were presented at the April, 1996, meeting of the Iowa Academy of Science, and the entire study was presented at the May, 1997, meeting of the Midwestern Psychological Association. We thank Nelson Cowan, William Johnston, and Neil Mulligan for helpful comments on an earlier version of this paper. We also thank Elizabeth Andre, Alison Bateson, Kelli Bendickson, Karla Benson, Katie Bock, Amanda Easton, Dana Hartwigsen, Brenda Jacobus, Patricia Schmidt, Molly White, and Steve Willis for their assistance in collecting the data. Correspondence concerning this article may be addressed to either author at the Department of Psychology, Iowa State University, Ames, IA 50011-3180 (e-mail: bcrabb@)iastate. edu orvjdark@iastate.edu).
}

argued, however, that whereas attentional processing at encoding is necessary for both explicit and conceptual implicit memory tests, it is less important for perceptual implicit memory tests (e.g., Debner \& Jacoby, 1994; Jacoby, Lindsay, \& Toth, 1992; Jacoby, Toth, \& Yonelinas, 1993; Jacoby \& Whitehouse, 1989). An even stronger position is that both encoding and retrieval for perceptual implicit memory occur automatically as the result of preattentive processing (Jelcic, Bonke, Wolters, \& Phaf, 1992; Parkin, Reid, \& Russo, 1990; Parkin \& Russo, 1990; Tulving \& Schacter, 1990).

A relatively large literature shows that performance on perceptual implicit memory tests is less affected by manipulations of attentional processing at encoding than performance on either conceptual implicit or explicit tests. Levels of processing manipulations show higher levels of performance as a function of deeper processing at encoding on explicit memory tests (e.g., Craik \& Tulving, 1975 ) and conceptual implicit memory tests (e.g., Blaxton, 1989), but level of processing at encoding does not affect performance on perceptual tests (e.g., Bergman, 1996; Jacoby \& Dallas, 1981; though see Brown \& Mitchell, 1994, for an account of an effect under certain circumstances). A number of studies have also demonstrated that whereas performance on explicit memory tests and conceptual implicit memory tests decreases sharply when attention is divided at encoding, little or no effect is shown on perceptual implicit memory tests (Mulligan, 1998 ; Mulligan \& Hartman, 1996; Musen, 1991; Parkin et al., 1990; Parkin \& Russo, 1990; Smith \& OscarBerman, 1990). For example, Mulligan and Hartman (1996) demonstrated that the presence of a digit-detection task during encoding of words greatly reduced later memory for the words as measured by a conceptual implicit memory test (category exemplar production) and two explicit tests (category cued recall and word-fragment cued recall) but not by a perceptual implicit memory test (word-fragment completion). Mulligan (1998) showed that 
increasing the amount of information maintained in working memory during encoding of words reduced performance on a conceptual implicit memory test for the words (category exemplar production) but not on a perceptual implicit memory test (word-fragment completion).

The levels of processing studies demonstrate that perceptual implicit memory does not vary directly with the type of attentional encoding. The divided attention studies demonstrate that perceptual implicit memory does not vary directly with the relative amount of attentional encoding, but the divided attention studies do not demonstrate perceptual implicit memory without any attentional encoding because the subjects were instructed to attend to all the stimuli. A focused attention paradigm must be used to gather evidence that only preattentive encoding is needed for perceptual implicit memory. In a focused attention paradigm, more information is presented than can be processed easily, and subjects are instructed to process only a subset of the available information. Some information is to be attended and some is to be ignored. Thus, in a focused attention paradigm, it is possible to have unattended stimuli, which presumably receive only preattentive processing.

Eich (1984) employed a type of focused attention paradigm called dichotic listening, in order to assess whether there was evidence for implicit memory for ignored words. While subjects were shadowing an essay presented to the attended ear, modifier-homophone pairs were presented in the unattended ear. The modifier biased the lowfrequency meaning of the homophone (e.g., SEA instead of SEE). A subsequent recognition test demonstrated no explicit memory for the homophones, but when subjects were asked to spell words (a conceptual implicit memory test), they were more likely to give the low-frequency spelling of homophones previously presented in the unattended ear than they were to give the low-frequency spelling to new, unpresented words. Although Eich concluded that the unattended words had been automatically encoded and that this automatic, preattentive encoding had produced the bias toward low-frequency spelling of the unattended words, his methodology has been criticized on a number of grounds, and it has been suggested that the words classified as "unattended" were likely to have been attended at encoding (Cowan, 1995; Holender, 1986; Mitchell, Doyle, \& Holthouser, 1995; Wood, Stadler, \& Cowan, 1997). Indeed, Mitchell et al. attempted to control for possible confounds and failed to replicate Eich's results in any of seven experiments; Wood et al. only replicated Eich's results when the word presentation rate was slow and there was the possibility that attention could switch between the channels.

Hawley and Johnston (1991) employed a focused attention paradigm in order to examine the extent to which the encoding tapped in a perceptual implicit memory test depended directly on awareness at encoding. Subjects were presented $33-\mathrm{msec}$ and 66-msec displays consisting of words surrounded by digits (e.g., 6 wORD 2). The duration manipulation was intended to vary the subjects' awareness of the words by controlling the availability of perceptual information. Subjects' awareness of the words was also manipulated by varying the amount of attention devoted to the words. One third of the subjects were asked to report the presented word on selected test trials, one third were asked to report the sum of the numbers on selected test trials, and one third were cued to do one or the other equally often on the selected test trials. Subjects in the word-only condition were classified as allocating $100 \%$ of attentional processing to the words, those in the sum-only condition were classified as allocating $0 \%$ of attentional processing to the words, and those in the mixed condition were classified as allocating $50 \%$ of attentional processing to the words. Perceptual implicit memory for the words was measured in terms of performance on a perceptual fluency (or perceptual identification) task. The results indicated reliable main effects of both exposure duration (higher levels of perceptual implicit memory with the 66-msec duration) and amount of attentional processing allocated during encoding (the level of perceptual implicit memory increased as attention increased from $0 \%$ to $100 \%$ ). Reliable perceptual implicit memory was found in the $100 \%$ attentional processing group (at both exposure durations) and in the $50 \%$ attentional processing group when words were presented for $66 \mathrm{msec}$.

Hawley and Johnston (1991) focused on the relationship between awareness and perceptual implicit memory rather than the nature of the encoding as attended or unattended. As a result, they used extremely data-limited displays (see Norman \& Bobrow, 1975). Although their results suggested that attentional encoding is necessary, the procedure may have underestimated the contribution of preattentive encoding of unattended words because of the extremely data-limited presentation conditions. Even preattentive processes require some minimal amount of data with which to work (Wickens, 1984). Preattentive processing of less data-limited, but still unattended, stimuli might support implicit perceptual memory.

Eich (1984) and Hawley and Johnston (1991) employed focused attention paradigms, but their results provided different answers to the question of whether there is evidence for implicit perceptual memory for unattended words. Our goal in the present study was to further examine that question. In order to determine whether a stimulus was attended or unattended, we used a focused attention encoding task in which subjects were to verbally report the word in a briefly presented pair of words that was preceded by a spatial precue (cf. Dark, Vochatzer, \& VanVoorhis, 1996). The focused attention task was followed either by a word-stem completion task or by a perceptual fluency task, both of which are assumed to measure perceptual implicit memory.

Both words in the pair that were presented as part of the focused attention encoding task were considered to be "old," or studied, words on the subsequent perceptual implicit memory test. Although the precued word was the target and the other word was the foil, the focused attention task was sufficiently difficult so that not all targets 
were reported and some foils were reported (cf. the neutral and unrelated conditions of Dark et al., 1996). Therefore, any word that was verbally reported by subjects during the focused attention task was classified as "attended," regardless of whether it was the target or the foil. Any word that was not reported was classified as "unattended," even if it was the target. The logic underlying this method of determining whether a word was attended or unattended is that a word which is reported must have been processed attentionally and thus was attentionally encoded. The possibility that some unreported words were encoded attentionally will be considered in the Discussion section.

The extent to which data limitations in preattentive processing might be operating was addressed by varying the amount of time $(100,200$, or $300 \mathrm{msec})$ that the words were presented during the focused attention task. Although some researchers have found an effect of exposure duration on implicit memory for fully attended words (e.g., von Hippel \& Hawkins, 1994), others have not (e.g., Hirshman \& Mulligan, 1991). Exposure duration was manipulated primarily to assess its effect on implicit memory for the unattended words. The goal was to provide sufficient data on which the preattentive processes could operate while still limiting duration so that it would be unlikely that both words were attended.

Different outcomes on the perceptual implicit memory tests were predicted, depending on whether perceptual implicit memory might be the result of preattentive or attentional processing at encoding. If perceptual implicit memory is due to preattentive processing alone, it might be affected by duration at encoding, but whether or not a word is verbally reported (attended) during the focused attention task should not affect the level of perceptual implicit memory; that is, although increasing the amount of time that words are presented might increase perceptual implicit memory, if preattentive processing is sufficient, there should be no difference in the level of perceptual implicit memory for attended versus unattended words. If, on the other hand, perceptual implicit memory is due to attentional processing at encoding, whether or not a word is verbally reported during the focused attention task should affect the level of perceptual implicit memory. Specifically, there only should be evidence of perceptual implicit memory for reported (attended) words. Furthermore, increasing the exposure duration should not affect the level of perceptual implicit memory for unattended words, which should remain at zero.

\section{METHOD}

\section{Subjects}

The subjects were 144 undergraduate students at Iowa State University enrolled in introductory psychology courses. They received extra credit for their participation. All subjects reported normal or corrected-to-normal vision and fluency in English.

\section{Design}

Twenty-four subjects were assigned to each of six betweensubjects conditions derived from the orthogonal combination of the three durations $(100,200,300 \mathrm{msec})$ used in the focused attention encoding task and the two implicit memory tests (word-stem completion and perceptual fluency). The $100-\mathrm{msec}$ conditions were run in one academic semester, and the $200-$ and $300-\mathrm{msec}$ conditions were run in the subsequent academic semester. The within-subjects variables for the implicit memory tests were word type (old vs. new) and encoding status (attended vs. unattended). Old words were classified as attended versus unattended by whether or not they were reported during the focused attention task. Although new words for a subject were not presented during the encoding task and, therefore, could not be either attended or unattended, the words were classified as attended versus unattended by whether or not they were reported by a yoked subject for whom they were old words. The yoking procedure is described in more detail in the Results section.

\section{Apparatus}

The Micro Experimental Laboratory software (Schneider, 1988) was used for timing and stimulus presentation on a Zenith 386 computer. A condenser microphone and response box were used to register when a verbal response was made. Verbal accuracy was recorded by an experimenter. All stimuli were presented as white lower case characters on a black background. The largest character was roughly $0.5 \mathrm{~cm}$ in height and $0.3 \mathrm{~cm}$ in width. The subjects were seated approximately $40 \mathrm{~cm}$ from the monitor and were encouraged to sit up straight in the chair. The largest stimulus displays, 3 rows by 11 characters, subtended roughly $3^{\circ}$ of visual angle in height and $5^{\circ}$ in width.

\section{Stimuli}

A pool of 120 words was selected from Roediger, Weldon, Stadler, and Riegler (1992, Experiment 3). Half of the words were high frequency and half were low frequency; the words ranged in length from 5 to 11 letters. The words were divided into four sets of 30 words each so that the sets were approximately equal along the dimensions of word length (average per set $=7.2, S D=.04$ ), frequency (50\% high and 50\% low), and initial letter. In addition, the words were matched in terms of imagery value (Paivio, Yuille, \& Madigan, 1968). Imagery values ranged from 2 to 6.9 , with an average value of $4.7(S D=.05)$ within each set.

For each subject, two sets were presented in the focused attention task and therefore were old words. One set ( 30 words) was presented as targets (the precued words), and one set was presented as foils (the uncued words). The remaining two sets were not presented in the focused attention task and therefore functioned to provide the new word baselines in the implicit memory tests. However, in order to allow the yoking described in the Results section, one set of new words was treated as targets, and one set was treated as foils. The sets were counterbalanced across subjects so that each word occurred equally often as an old target, an old foil, a new yoked target, and a new yoked foil.

\section{Procedure}

The subjects engaged in two tasks: the initial focused attention encoding task, and a perceptual implicit memory test-either wordstem completion or perceptual fluency. Instructions were given prior to each task. The subjects were allowed to take a short break between tasks if they so desired.

Focused-attention task. All subjects initially engaged in a focused attention encoding task in which they were to report the spatially precued word out of two briefly presented words. There were 30 trials. Each trial began with a double plus sign fixation point for 
Table 1

Mean Proportions of Targets and Foils Reported During the Focused Attention Task as a Function of Exposure Duration

\begin{tabular}{|c|c|c|c|c|c|c|}
\hline & \multicolumn{6}{|c|}{ Exposure Duration (msec) } \\
\hline & \multicolumn{2}{|c|}{100} & \multicolumn{2}{|c|}{200} & \multicolumn{2}{|c|}{300} \\
\hline & $M$ & $S E$ & $M$ & $S E$ & $M$ & $S E$ \\
\hline Targets & .462 & .022 & .655 & .026 & .820 & .017 \\
\hline Foils & .322 & .024 & .207 & .025 & .235 & .029 \\
\hline
\end{tabular}

$750 \mathrm{msec}$. The fixation point was followed by a 500 -msec blank screen. Following the blank screen, the fixation reappeared along with a rectangular bar "cue" two lines above or below the fixation point. The cue defined the target word for that particular trial. A word pair occurred $100 \mathrm{msec}$ after cue onset; one word was presented directly above and one directly below the fixation point. The word pair was presented for 100,200 , or $300 \mathrm{msec}$ before being replaced by two rows of Xs. The cue, fixation, and Xs remained on the screen until a response was made; the intertrial interval was $6,000 \mathrm{msec}$. The subjects were instructed that their task was to report the word cued by the bar (the target). They also were instructed that if they saw the uncued word (the foil) in addition to or instead of the target, they were to report it and to identify it as the "other" word.

Word-stem completion. In the word-stem completion task, the subjects completed 120 three-letter stems. The stems were derived from the 60 old words presented in the focused attention task ( 30 targets and 30 foils) and the 60 new words. One random ordering of stems was generated, with the restriction that within every 8 stems, 2 stems would be derived from each of the four sets of words. The same ordering was presented on a printed response sheet to each subject. The subjects were instructed to complete each stem in writing with the first word that came to their minds. They were given $12 \mathrm{sec}$ to complete each stem, after which the computer sounded a tone indicating that they were to proceed to the next stem. The subjects used a cover sheet to hide the upcoming stems and were not allowed to work ahead or to go back to previous stems.

Perceptual fluency. In the perceptual fluency task, 120 trials were presented. Each trial began with a fixation point for $500 \mathrm{msec}$. Following fixation, a word was presented for $33 \mathrm{msec}$ and was followed by a row of $\mathrm{Xs}$, which remained on until a response was made. Of these words, 60 were the old words from the encoding task ( 30 targets and 30 foils) and 60 were the new words. The subjects were instructed to verbally identify the words, and their responses were recorded by the experimenter. All subjects saw the words in the same order; the order corresponded to that on the word-stem completion response sheet.

The subjects were debriefed after the implicit memory test. The entire procedure took approximately $45 \mathrm{~min}$.

\section{RESULTS}

An alpha level of .05 was used for all analyses.

\section{Focused Attention Task}

Table 1 shows the mean proportion of old words (targets and foils) identified during the focused attention encoding task as a function of exposure duration $(100,200$, and $300 \mathrm{msec}$ ). An analysis of variance (ANOVA) with word type as a within-subjects variable and exposure duration as a between-subjects variable showed a reliable main effect of word type $\left[F(1,141)=338.71, M S_{\mathrm{e}}=.0325\right]$, with higher report of targets than of foils; a reliable main effect of exposure duration $\left[F(2,141)=20.44, M S_{\mathrm{e}}=\right.$ $.0228]$, with higher report at the longer durations; and a reliable word type $\times$ exposure duration interaction $\left[F(2,141)=38.50, M S_{\mathrm{e}}=0.0325\right]$. The simple main effect of word type was reliable for all exposure durations, but the magnitude of the effect increased with exposure duration. That is, the selection task became easier as exposure duration increased.

\section{Implicit Memory Tests}

During the implicit memory tests, the subjects were asked to respond both to old words, those presented in the focused attention task, and to new words, those not presented in the focused attention task. The old words were classified as "attended" if they had been reported during the focused attention task and "unattended" if they had not, regardless of whether the word was a target or a foil. Because of the possibility of item differences between attended and unattended words that might occur if some words were easier to identify than others, the subjects were yoked in pairs such that the old words for each member of the pair were the new words for the other member. The encoding status of each new word for each subject was set to the same level (attended vs. unattended) that it had when it was an old word for the other subject. In this way, each subject's new words were classed as attended versus unattended. Thus, for each yoked pair of subjects, the attended old and attended new words comprised the same words and the unattended old and unattended new words comprised the same words. ${ }^{1}$

Word-stem completion. For each stem, a response was scored as a "completion" if the response was one of the words from the 120-word pool. The mean word-stem completion rates as a function of word type (old, new), encoding status (attended, unattended), and focused attention exposure duration $(100,200,300 \mathrm{msec})$ are shown in Figure 1. An ANOVA was performed with word type and encoding status as within-subjects variables and focused attention exposure duration as a between-subjects variable. ${ }^{2}$ There was a reliable main effect of word type $\left[F(1,69)=92.13, M S_{\mathrm{e}}=0.0046\right]$, a reliable main effect of encoding status $\left[F(1,69)=108.55, M S_{\mathrm{e}}=0.0057\right]$, and a reliable word type $\times$ encoding status interaction $\left[F(1,69)=39.06, M S_{\mathrm{e}}=0.0064\right]$. The simple main effect of word type for attended words was reliable, indicating higher completion rates for old attended words than for new attended words. The simple main effect of word type for unattended words was not reliable. The reliable difference between attended old and new words demonstrates perceptual implicit memory for attended words, whereas the lack of a reliable difference between unattended old and new words demonstrates no perceptual implicit memory for unattended words.

Exposure duration did not produce any reliable effects in the overall ANOVA. The impact of exposure duration 


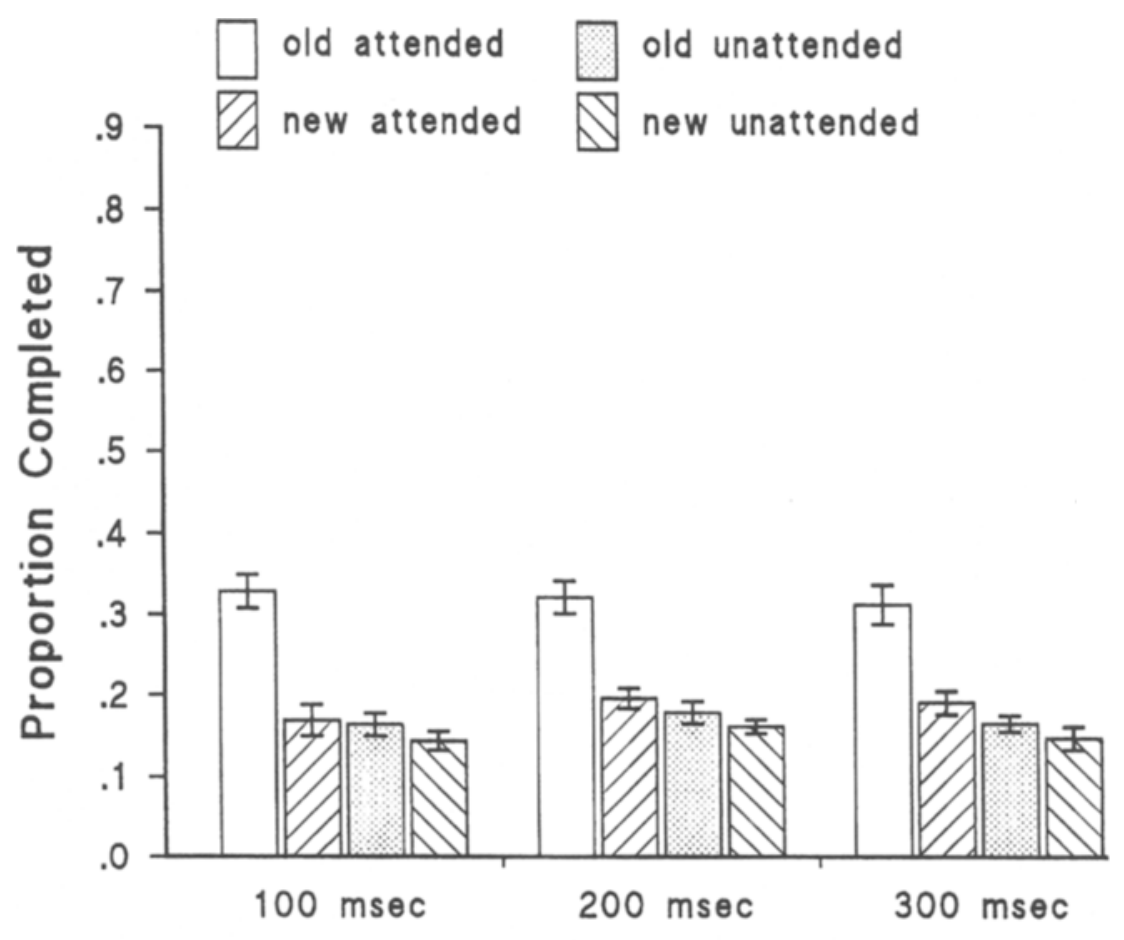

Focused Attention Exposure Duration

Figure 1. Mean proportion of word stems completed as a function of word type (old and new), encoding status (attended and unattended), and focused attention exposure duration (100, 200, and $300 \mathrm{msec})$.

on implicit memory was directly examined by computing priming scores. Priming was computed by subtracting the proportion of new word stems completed from the proportion of old word stems completed for each level of encoding status. Word-stem priming as a function of word type, encoding status, and focused attention exposure duration is shown in the top two rows of Table 2 . Priming was reliably greater than zero for attended words at each exposure duration, and a one-way ANOVA showed no differences among the groups. Priming was not reliably greater than zero for any unattended condition, and a one-way ANOVA showed no differences among the groups. Thus, the level of perceptual implicit memory depended only on whether the stimulus was attended and not on exposure duration at encoding.

Perceptual fluency. The mean identification rates as a function of word type (old, new), encoding status (attended, unattended), and focused attention exposure duration $(100,200,300 \mathrm{msec})$ are shown in Figure 2. An ANOVA was performed with word type and encoding status as within-subjects variables and focused attention exposure duration as a between-subjects variable. There was a reliable main effect of word type $[F(1,69)=32.65$, $\left.M S_{\mathrm{e}}=0.0065\right]$, a reliable main effect of encoding status $\left[\mathrm{F}(1,69)=173.17, M S_{\mathrm{e}}=0.0082\right]$, and a reliable word type $\times$ encoding status interaction $[F(1,69)=19.68$,

Table 2

Priming Scores for Word-Stem Completion and Perceptual Fluency as a Function of Encoding Status and Focused Attention Exposure Duration

\begin{tabular}{|c|c|c|c|c|c|c|c|}
\hline \multirow[b]{3}{*}{ Task } & \multirow[b]{3}{*}{ Encoding Status } & \multicolumn{6}{|c|}{ Exposure Duration (msec) } \\
\hline & & \multicolumn{2}{|c|}{100} & \multicolumn{2}{|c|}{200} & \multicolumn{2}{|c|}{300} \\
\hline & & $M$ & $S E$ & $M$ & $S E$ & $M$ & $S E$ \\
\hline \multirow[t]{2}{*}{ Word-stem completion } & attended & $.160^{*}$ & .026 & $.126^{*}$ & .027 & $.121^{*}$ & .026 \\
\hline & unattended & .020 & .016 & .017 & .014 & .017 & .015 \\
\hline \multirow[t]{2}{*}{ Perceptual fluency } & attended & $.095^{*}$ & .027 & $.126^{*}$ & .031 & $.100^{*}$ & .022 \\
\hline & unattended & -.023 & .019 & .009 & .019 & .019 & .026 \\
\hline
\end{tabular}

Note-Priming scores are old minus new for each condition. ${ }^{*}$ Reliably different from zero $(p<.05)$. 


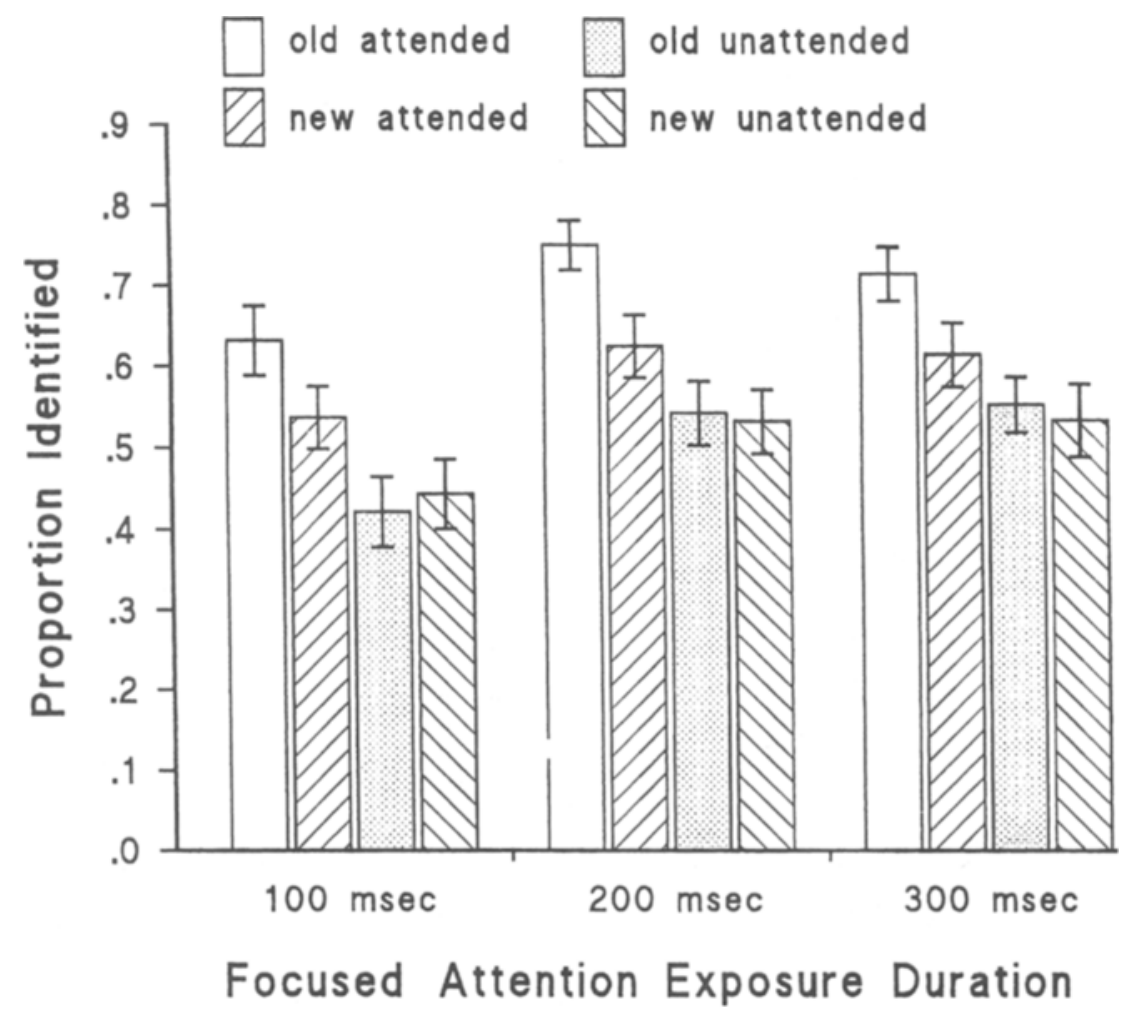

Figure 2. Mean proportion of words identified during the perceptual fluency task as a function of word type (old and new), encoding status (attended and unattended), and focused attention exposure duration $(100,200$, and $300 \mathrm{msec})$.

$\left.M S_{\mathrm{e}}=0.0100\right]$. The simple main effect of word type for attended words was reliable, indicating higher completion rates for old attended words than for new attended words. The simple main effect of word type for unattended words was not reliable. As with word-stem completion, the reliable difference between attended old and new words demonstrates perceptual implicit memory for attended words, whereas the lack of a reliable difference between unattended old and new words demonstrates no perceptual implicit memory for unattended words.

There was a marginally reliable main effect of exposure duration $\left[F(2,69)=2.66, M S_{\mathrm{e}}=0.1216, p=.08\right]$, with poorer performance in the $100-\mathrm{msec}$ group, but no interaction involving exposure duration was reliable (all $F_{\mathbf{s}}<$ 1.00 ). The $100-\mathrm{msec}$ group had 3 subjects who identified fewer than $25 \%$ of the words during the perceptual fluency task. No other group had any subjects who performed so poorly.

As with the word-stem completion data, the impact of exposure duration on implicit memory was directly examined by computing priming scores. Perceptual fluency priming as a function of word type, encoding status, and focused attention exposure duration is shown in the bottom two rows of Table 2. Priming was reliably greater than zero for attended words at each exposure duration, and a one-way ANOVA showed no differences among the groups. Priming was not reliably greater than zero for any unattended condition, and a one-way ANOVA showed no differences among the groups. Thus, as with the wordstem completion results, the level of perceptual implicit memory depended only on whether the stimulus was attended and not on exposure duration at encoding.

\section{DISCUSSION}

The present study was designed to investigate whether words must be encoded attentionally in order for them to affect performance on a later perceptual implicit memory test. The procedure allowed a clear differentiation between attended and unattended words that had been presented at different exposure durations during the encoding task. The results demonstrated perceptual implicit memory for attended words, but no perceptual implicit memory for unattended words. Furthermore, the presentation duration at encoding had no reliable effect on the magnitude of implicit memory priming for either attended words or unattended words. A similar pattern was found with two different tasks: word-stem completion and perceptual fluency. Thus, the conclusion that attentional encoding is necessary for perceptual implicit memory is not peculiar to a specific type of perceptual implicit memory test. (See MacDonald \& MacLeod, 1998, for similar findings with a rapid reading task.)

The present results demonstrate that words must receive at least some attentional processing at encoding in order for them to affect performance on a later perceptual 
implicit memory test. Although it could be argued that the old words classified as unattended did in fact receive some attentional processing, just not enough to support the immediate verbal report of the words, that possibility in no way changes the conclusions. Even if the "unattended" old words did receive some attentional processing, the lack of implicit memory for these words indicates that there is some necessary amount of attentional processing of a word that must be accomplished at encoding before it can influence performance on a later perceptual implicit memory test. The results confirm the observation of Hawley and Johnston (1991) that only when a stimulus undergoes sufficient attentional processing to support awareness of stimulus identity at encoding will there be evidence of later perceptual implicit memory of the stimulus. In this way, even perceptual implicit memory appears to be similar to explicit memory (cf. Shiffrin \& Schneider, 1977).

It also could be argued that because we defined "attended" in terms of the subject's making an overt articulatory response, we have confounded attention with the response. Perhaps the results do not reflect the difference between attended and unattended words, but rather the difference between words to which an overt response has been made and words to which no overt response has been made. Although we cannot rule out this possibility in the present research, others have shown reliable implicit memory for stimuli that were attended but to which no overt response was made (e.g., Hawley \& Johnston, 1991; MacDonald \& MacLeod, 1998, Experiment 2; Mulligan, 1998; Mulligan \& Hartman, 1996). Even if the implicit memory that we obtained were the result of the overt response, however, this would not change the basic conclusion: Some level of attentional processing at encoding (perhaps the level needed to make a response) is necessary to support perceptual implicit memory.

The present results cannot be incorporated easily into the most prominent multiple-memory explanation of implicit memory. According to Tulving and Schacter (1990), a characteristic of the perceptual representation system (the memory system hypothesized to underlie performance on perceptual implicit memory tests) is that ". . . its operations are disconnected from consciousness, and its products do not provide a basis of awareness of previous experience" (p. 305). To the degree that memory system "operations" include encoding and to the degree that preattentive processes are unconscious, this statement predicts that there should be reliable perceptual implicit memory for unattended stimuli. The present study provides no support for that prediction.

The present results can be incorporated easily into the transfer appropriate processing explanation of implicit memory phenomena (Blaxton, 1989; Roediger, 1990; Roediger et al., 1989). The transfer appropriate processing framework (Morris, Bransford, \& Franks, 1977) states that performance on a memory test is directly related to the degree to which the cognitive processes invoked by the test correspond to the cognitive processes engaged in at encoding. Perceptual tests rely heavily on perceptual processes, whereas conceptually driven tests rely heavily on semantic or meaning-based processes (Blaxton, 1989). The present results suggest that the perceptual processing engaged in at encoding must be attentional in order for it to affect performance on a later perceptual implicit memory test. Preattentive perceptual processing alone at encoding is not enough to affect performance on a later perceptual implicit memory test.

The results of the present study add to the literature examining the relationship between perceptual implicit memory and type and amount of attentional processing at encoding. Weldon (1991) suggested that lexical access at encoding is necessary for perceptual implicit memory. The present results show that attention at encoding is necessary for perceptual implicit memory. Our results and Weldon's support the hypothesis that lexical access requires attention (see, e.g., Herdman, 1992; McCann, Folk, \& Johnston, 1992). Research employing levels of processing and divided attention paradigms further suggests that perceptual implicit memory requires some minimal amount of attentional processing at encoding, but that there is no benefit from any further amount of attentional processing (see Mulligan, 1998; Mulligan \& Hartman, 1996). Taken together, these studies support the conclusion that perceptual implicit memory tests reflect only the initial attentional perceptual processing at encoding (lexical access in the case of words), and they do not reflect any further elaborative or semantic processing. Although when Shiffrin and Schneider (1977) stated that changes in long-term memory require attention, they were referring to explicit memory, the present data suggest that all long-term changes to memory require attention.

\section{REFERENCES}

BERGMAN, E. T. (1996, November). The levels of processing effect on an implicit memory task: Analysis of an intermittent phenomenon. Poster presented at the annual meeting of the Psychonomic Society, Chicago.

BLAXTON, T. A. (1989). Investigating dissociations among memory measures: Support for a transfer appropriate processing framework. Journal of Experimental Psychology: Learning, Memory, \& Cognition, 15, 657-668.

Brown, A. S., \& Mitchell, D. B. (1994). A reevaluation of semantic versus nonsemantic processing in implicit memory. Memory \& Cognition, 22, 533-541.

Cowan, N. (1995). Attention and memory: An integrated framework. New York: Oxford University Press.

Craik, F. I. M., \& Tulving, E. (1975). Depth of processing and the retention of words in episodic memory. Journal of Experimental Psychology: General, 104, 268-294.

Dark, V. J., Vochatzer, K. G., \& VanVoorhis, B. A. (1996). Semantic and spatial components of selective attention. Journal of Experimental Psychology: Human Perception \& Performance, 22, 63-81.

DEBNER, J. A., \& JACOBY, L. L. (1994). Unconscious perception: Attention, awareness; and control. Journal of Experimental Psychology: Learning, Memory, \& Cognition, 20, 304-317.

EICH, E. (1984). Memory for unattended events: Remembering with and without awareness. Memory \& Cognition, 12, 105-111.

Fisk, A. D., \& SCHNEIDER, W. (1984). Memory as a function of attention, level of processing, and automatization. Journal of Experimental Psychology: Learning, Memory, \& Cognition, 10, 181-197. 
HAWLEY, K. J., \& JOHNSTON, W. A. (1991). Long-term perceptual memory for briefly exposed words as a function of awareness and attention. Journal of Experimental Psychology: Human Perception \& Performance, 17, 807-815.

Herdman, C. M. (1992). Attentional demands of visual recognition in naming and lexical decisions. Journal of Experimental Psychology: Human Perception \& Performance, 18, 460-470.

Hirshman, E., \& Mulligan, N. (1991). Perceptual interference improves explicit memory but does not enhance data-driven processing Journal of Experimental Psychology: Learning, Memory, \& Cognition, 17, 507-513.

HOLENDER, D. (1986). Semantic activation without conscious identification in dichotic listening, parafoveal vision, and visual masking: A survey and appraisal. Behavioral \& Brain Sciences, 9, 1-66.

JACOBY, L. L., \& Dallas, M. (1981). On the relationship between autobiographical memory and perceptual learning. Journal of Experimental Psychology: General, 110, 306-340.

JACOBY, L. L., LiNDSAY, D. S., ToTH, J. P. (1992). Unconscious influences revealed: Attention, awareness, and control. American Psychologist, 47, 802-809.

JACOBY, L. L., ToTH, J. P., \& Yonelinas, A. P. (1993). Separating conscious and unconscious influences of memory: Measuring recollection. Journal of Experimental Psychology: General, 122, 139-154.

JACOBY, L. L., \& WhITEHOUSE, K. (1989). An illusion of memory: False recognition influenced by unconscious perception. Journal of Experimental Psychology: General, 118, 126-135.

Jelcic, M., Bonke, B., Wolters, G., \& PhaF, R. H. (1992). Implicit memory for words presented during anesthesia. European Journal of Cognitive Psychology, 4, 71-80.

MacDonald, P., \& MACLEOD, C. M. (1998). The influence of attention at encoding on direct and indirect remembering. Acta Psychologica, 98, 298-310.

MCCann, R., Folk, C. L., Johnston, J. C. (1992). The role of spatial attention in visual word processing. Journal of Experimental Psychology: Human Perception \& Performance, 18, 1015-1029.

Mitchell, D. B., Doyle, J. E., \& Holthouser, L. W. (1995, November). Unattended input in dichotic listening: Unforgettable or unavailable? Paper presented at the annual meeting of the Psychonomic Society, Los Angeles.

MorRis, D. C., Bransford, J. D., \& FranKs, J. J. (1977). Levels of processing versus transfer appropriate processing. Journal of Verbal Learning \& Verbal Behavior, 16, 519-533.

Mulligan, N.W. (1998). The role of attention during encoding on implicit and explicit memory. Journal of Experimental Psychology: Learning, Memory, \& Cognition, 24, 27-47.

Mulligan, N. W., \& Hartman, M. (1996). Divided attention and indirect memory tests. Memory \& Cognition, 24, 453-465.

MuSEN, G. (1991). Effects of verbal labeling and exposure duration on implicit memory for visual patterns. Journal of Experimental Psychology: Learning, Memory, \& Cognition, 17, 954-962.

Norman, D., \& BoBrow, D. (1975). On data limited and resource limited processing. Journal of Cognitive Psychology, 7, 44-60.

Paivio, A., Yuille, J. C., \& Madigan, S. (1968). Concreteness, imagery, and meaningfulness values for 925 nouns. Journal of Experimental Psychology Monographs, 78 (1, Pt. 2).

PARKIN, A. J., ReID, T. K., \& Russo, R. (1990). On the differential nature of implicit and explicit memory. Memory \& Cognition, 18, 507-514.
PARKIN, A. J., \& Russo, R. (1990). Implicit and explicit memory and the automatic/effortful distinction. European Journal of Cognitive Psychology, 2, 71-80.

Rock, I., \& GuTMan, D. (1981). The effect of inattention on form perception. Journal of Experimental Psychology: Human Perception \& Performance, 7, 275-285.

ROEDIGER, H. L., III. (1990). Implicit memory: Retention without awareness. American Psychologist, 45, 1043-1056.

Roediger, H. L., III, Weldon, M. S., \& Challis, B. H. (1989). Explaining dissociations between implicit and explicit measures of retention: A processing account. In H. L. Roediger, III \& F. I. M. Craik (Eds.), Varieties of memory and consciousness: Essays in honour of Endel Tulving (pp. 3-41). Hillsdale, NJ: Erlbaum.

Roediger, H. L., III, Weldon, M. S., Stadler, M. L., \& Riegler, G. L. (1992). Direct comparison of two implicit memory tests: Word fragment and word stem completion. Journal of Experimental Psychology: Learning, Memory, \& Cognition, 18, 1251-1269.

SCHNEIDER, W. (1988). Micro Experimental Laboratory: An integrated system for IBM PC compatibles. Behavior Research Methods, Instruments, \& Computers, 20, 206-217.

SHiffrin, R. M., \& SCHNeIDER, W. (1977). Controlled and automatic human information processing II: Perceptual learning, automatic encoding, and a general theory. Psychological Review, 84, 127-190.

SMith, M. E., \& OsCaR-BERman, M. (1990). Repetition priming of words and pseudowords in divided attention and in amnesia. Journal of Experimental Psychology: Learning, Memory, \& Cognition, 16, 1033-1042.

Tulving, E., \& Schacter, D. L. (1990). Priming and human memory systems. Science, 247, 301-306.

von HipPel, W., \& Hawkins, C. (1994). Stimulus exposure time and perceptual memory. Perception \& Psychophysics, 56, 525-535.

WELDON, M. S. (1991). Mechanisms underlying priming on perceptual tests. Journal of Experimental Psychology: Learning, Memory, \& Cognition, 17, 526-541.

WiCKENS, C. D. (1984). Processing resources in attention. In R. Parasuraman \& D. R. Davies (Eds.), Varieties of attention (pp. 63-102). Orlando, FL: Academic Press.

Wood, N. L., Stadler, M. A., \& Cowan, N. (1997). Is there implicit memory without attention? A reexamination of task demands in Eich's (1984) procedure. Memory \& Cognition, 25, 772-779.

\section{NOTES}

1. The yoking procedure was designed to account for potential differences in the implicit memory analyses in the items comprising attended and unattended words. As pointed out by William Johnston, it should be noted that this procedure does not account for idiosyncratic differences in how specific individuals process specific words.

2 . Several reviewers questioned why the data were not analyzed with an ANOVA in which encoding duration $(100,200$, and $300 \mathrm{msec})$, type of word at encoding (target or foil), report status (reported and nonreported), and type of word at test (old and new) were variables. If we required that each subject have at least two observations per cell, the result is that 2 subjects must be tossed at the 100 -msec duration, 14 at the 200 -msec duration, and 18 at the 300 -msec duration. However, the $100-$ msec duration data were examined in this way for both word-stem completion and perceptual fluency. The analyses are shown in the Appendix. 


\section{APPENDIX}

\section{Word-Stem Completion}

The 100-msec exposure duration data were analyzed with an ANOVA in which type of word at encoding (target vs. foil), report status (reported vs. nonreported), and type of word at test (old vs. new) were variables. The mean proportion of completed word stems for each condition is shown in the top half of Table A1. There was a marginally reliable effect of type of word at encoding $\left[F(1,21)=4.03, M S_{\mathrm{e}}=0.0100, p=.06\right]$, with higher completion for targets; a reliable main effect of report status $\left[F(1,21)=26.66, M S_{\mathrm{e}}=0.0153\right]$, with higher completion of reported words; a reliable main effect of word type at test $\left[F(1,21)=39.79, M S_{\mathrm{e}}=0.0089\right]$, with higher completion of old words; and a reliable report status $\times$ word type at encoding interaction $\left[F(1,21)=19.07, M S_{\mathrm{e}}=0.0127\right]$. Although there was a tendency for targets to be completed at a higher proportion than foils, as can be seen in Table Al, the major influence on whether a stem was completed with an old word was whether or not the old word had been reported at encoding.

\section{Perceptual Fluency}

The 100-msec duration perceptual fluency data were analyzed in the same manner as that for the word-stem completion data. The mean proportion of identified words for each condition is shown in the bottom half of Table A1. There was a reliable main effect of report status $\left[F(1,21)=39.58, M S_{\mathrm{e}}=0.0265\right]$, with higher identification of reported word; a reliable main effect of word type at test $\left[F(1,21)=7.28, M S_{\mathrm{e}}=0.0157\right]$, with higher identification of old words; and a reliable report status $\times$ word type at encoding interaction $\left[F(1,21)=11.51, M S_{\mathrm{e}}=0.0164\right]$. Whether or not an old word was a target or a foil at encoding had no effect on the likelihood of its being identified during the perceptual fluency task. The major influence on whether a word was identified was whether or not it had been reported at encoding.

Table A1

Performance on Perceptual Implicit Memory Tasks for the 100-msec Duration Groups as a Function of Report Status, Word Type at Test, and Word Type at Encoding

\begin{tabular}{|c|c|c|c|c|c|c|c|c|c|}
\hline \multirow[b]{3}{*}{ Task } & \multirow[b]{3}{*}{ Target Status } & \multicolumn{4}{|c|}{ Old Words } & \multicolumn{4}{|c|}{ New Words } \\
\hline & & \multicolumn{2}{|c|}{ Target } & \multicolumn{2}{|c|}{ Foil } & \multicolumn{2}{|c|}{ Target } & \multicolumn{2}{|c|}{ Foil } \\
\hline & & $M$ & $S E$ & $M$ & $\overline{S E}$ & $M$ & $S E$ & $M$ & $\overline{S E}$ \\
\hline Word-stem completion & $\begin{array}{l}\text { reported } \\
\text { nonreported }\end{array}$ & $\begin{array}{l}.32 \\
.14\end{array}$ & $\begin{array}{l}.03 \\
.02\end{array}$ & $\begin{array}{l}.35 \\
.19\end{array}$ & $\begin{array}{l}.03 \\
.02\end{array}$ & $\begin{array}{l}.17 \\
.13\end{array}$ & $\begin{array}{l}.03 \\
.01\end{array}$ & $\begin{array}{l}.17 \\
.17\end{array}$ & $\begin{array}{l}.03 \\
.02\end{array}$ \\
\hline Perceptual fluency & $\begin{array}{l}\text { reported } \\
\text { nonreported }\end{array}$ & $\begin{array}{l}.63 \\
.38\end{array}$ & $\begin{array}{l}.05 \\
.05\end{array}$ & $\begin{array}{l}.62 \\
.43\end{array}$ & $\begin{array}{l}.06 \\
.05\end{array}$ & $\begin{array}{l}.53 \\
.40\end{array}$ & $\begin{array}{l}.04 \\
.05\end{array}$ & $\begin{array}{l}.49 \\
.44\end{array}$ & $\begin{array}{l}.05 \\
.04\end{array}$ \\
\hline
\end{tabular}

(Manuscript received June 16, 1997; revision accepted for publication April 21, 1998.) 